\title{
Factors Influencing Alzheimer's Disease Risk: Whether and How They are Related to the APOE Genotype
}

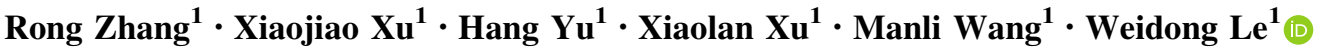

Received: 18 October 2021/Accepted: 25 November 2021/Published online: 11 February 2022

(C) The Author(s) 2022

\begin{abstract}
Alzheimer's disease (AD) is the most prevalent neurodegenerative disease featuring progressive cognitive impairment. Although the etiology of late-onset $\mathrm{AD}$ remains unclear, the close association of $\mathrm{AD}$ with apolipoprotein E (APOE), a gene that mainly regulates lipid metabolism, has been firmly established and may shed light on the exploration of $\mathrm{AD}$ pathogenesis and therapy. However, various confounding factors interfere with the $A P O E$-related $\mathrm{AD}$ risk, raising questions about our comprehension of the clinical findings concerning APOE. In this review, we summarize the most debated factors interacting with the $A P O E$ genotype and $\mathrm{AD}$ pathogenesis, depict the extent to which these factors relate to $A P O E$ dependent $\mathrm{AD}$ risk, and discuss the possible underlying mechanisms.
\end{abstract}

Keywords Apolipoprotein E - Alzheimer's disease - Ethnicity · Diet · Geographic factor · Aging · Gender

\section{Background}

Alzheimer's disease (AD) is one of the most prevalent and influential neurodegenerative diseases, characterized by typical pathological findings of beta-amyloid $(\mathrm{A} \beta)$ and tau plaques $[1,2]$. Featuring irreversible and progressive deterioration of cognitive function and mainly affecting

Weidong Le

wdle@sibs.ac.cn

1 Institute of Neurology, Sichuan Academy of Medical Sciences, Sichuan Provincial People's Hospital, University of Electronic Science and Technology of China,

Chengdu 611731, China the elderly, AD imposes an enormous burden on patients, communities, and healthcare systems. Unfortunately, as life expectancy increases, the population of AD patients is expanding rapidly. The number of AD patients in the USA is estimated to grow from 4.7 million to 13.8 million from 2010 to 2050 [3]. Other countries are believed to be confronted with a similar impact of AD.

Apolipoprotein E (APOE) is a multifunction protein that plays a crucial role in the intercellular and interstitial transport of lipid and the mediation of dynamic lipid levels and lipid metabolism [4]. APOE fulfills its function by forming a close connection with lipoproteins and their receptors. Besides, APOE is also involved in neurophysiological processes such as synapse development and remodeling. Two vital single nucleotide polymorphisms (SNPs) located in APOE coding regions, rs429358 (C>T) and $\mathrm{rs} 7412(\mathrm{C}>\mathrm{T})$, define the three major subtypes of $A P O E$ allele, $\varepsilon 2, \varepsilon 3$, and $\varepsilon 4$. Alteration of $\varepsilon 2, \varepsilon 3$, and $\varepsilon 4$ confers crucial variation on the protein structure of APOE, its physiological function, and its effect on related diseases $[5,6]$. Besides its crucial effect on lipid metabolism, $\varepsilon 4$ is the first, by far the most relevant and the most intensively studied risk gene for late-onset $\mathrm{AD}[6,7]$. APOE $\varepsilon 4$ carriers have a higher lifetime incidence of $A D$ and an earlier onset. In rough estimation, Farrer et al. found that individuals who carry one $\varepsilon 4$ allele bear a 2-4 fold AD risk, and those with two copies of $\varepsilon 4$ have an 8-12 fold AD risk [8].

Since the close association of $A P O E$ and $A D$ was explicitly established in 1993, many studies have explored the underlying mechanism. Although the exact mechanism remains obscure, it is widely acknowledged that APOE is extensively involved in various pathologic processes of AD. (1) A $\beta$-dependent pathways: APOE-related AD risk can be largely attributed to an alteration of protein deposition, for the APOE genotype is no longer 
significantly associated with the clinical phenotype after controlling for AD pathology [9]. APOE $\varepsilon 4$ carriers and $\varepsilon 4$ knock-in mice both manifest exacerbated $A \beta$ proteinopathy $[10,11]$. Experiments showed that Apoe/APOE co-precipitates with $\mathrm{A} \beta$ in mice and $\mathrm{AD}$ patients [12], APOE $\varepsilon 4$ may facilitate the aggregation both in vitro and in vivo $[13,14]$. Researchers also reported the more rapid formation of $A \beta$ oligomer as well as slower clearance of $\mathrm{A} \beta$ in $\varepsilon 4$ knock-in rats, which corresponds with the results from studies in $A P O E$ \&4 cells [15-17]. (2) A $\beta$-independent pathways: APOE $\varepsilon 4$ can up-regulate neuroinflammation, as reported in $\varepsilon 4$ carriers and knock-in mice [18, 19], possibly through regulation of glia [20-22]. APOE $\varepsilon 4$ is harmful to the integrity of the blood-brain barrier in mice [23], and bloodbrain barrier impairment of the hippocampus and medial temporal lobe, correlated with cognitive dysfunction, has been reported in human $\varepsilon 4$ carriers. Besides, the APOE genotype may alter the production of brain-derived neurotrophic factor and neuroprotective sirtuin, as well as energy expenditure [24-26].

$A P O E$-related $\mathrm{AD}$ risk can be influenced by various factors, such as ancestry, gender, environment, and diet. These factors may exert their influence through distinct mechanisms such as regulation of transcription or expression of $A P O E$, alteration of lipid metabolism, impacting the $\mathrm{AD}$ pathological process in which $A P O E$ is deeply involved. Previous epidemiological research provides abundant evidence to understand how these factors interact with $A P O E$-related $\mathrm{AD}$ risk and the possible physiological explanation of these interactions. Here, we provide an overall review of the most debated confounding factors and discuss how they are connected to APOE and the pathogenesis of $\mathrm{AD}$ (Fig. 1).

\section{Ethnicity and APOE}

The rough frequency ranges of the APOE $\varepsilon 2 / 3 / 4$ alleles are $(0-7) \% /(69-85) \% /(4-40) \%$ across the world [7], but this ratio varies significantly among different ethnicities (Table 1). Generally, the frequency of the $\varepsilon 2$ allele is relatively constant, which leads to the negative correlation of the $\varepsilon 3$ and $\varepsilon 4$ alleles [27]. The APOE $\varepsilon 4$ allele comprises a larger proportion in Central Africa (40\%), Oceania (37\%), and Australia (26\%), while in Europe and Asia, the $\varepsilon 4$ allele frequency ranges from $10 \%$ to $25 \%$, roughly positively related to the latitude of residence [7].

The ethnic background has a certain impact on AD risk, based on numerous epidemiological studies (Table 1). A 7-year longitudinal study based on the multi-ethnic population in New York established that, compared with Caucasians, African-American people [hazard ratio $(\mathrm{HR})=$ 2.6] and Caribbean Hispanic people $(\mathrm{HR}=2.3)$ are confronted with a significantly higher risk of $\mathrm{AD}$ [32]. Later, the cohort study conducted in Northern California included six ethnic groups further demonstrated that Asian Americans have the lowest incidence of $\mathrm{AD}$, followed by Caucasians, Pacific Islanders, and Latin Americans $(H R=1.25-1.29)$, then American Indians $(\mathrm{HR}=1.43)$, and the most affected African Americans $(\mathrm{HR}=1.73)$ [33]. Kevin and his team summarized $28,027,071$ beneficiaries of the Medicare Fee-for-Service to estimate the prevalence of $\mathrm{AD}$ and related dementias in different subgroups. The result showed that the order of ethnicities with prevalence from low to high is Asian and Pacific Islanders (8.4\%), American Indians and Alaska Natives $(9.1 \%)$, non-Hispanic Caucasians (10.3\%), Hispanics (12.2\%), and African Americans (13.8\%) [34]. Since these studies included and analyzed several confounding factors such as educational level, vascular diseases, and other comorbidities, the authors made it clear that the inequalities in $\mathrm{AD}$ incidence most likely result from the diversity of ethnic genetic backgrounds.

The meta-analysis by Farrer and colleagues found that African and Hispanic $\varepsilon 4$ carriers, compared with Caucasian $\varepsilon 4$ carriers, have a lower $A P O E$-related $\mathrm{AD}$ risk [8]. Meanwhile, Japanese $\varepsilon 4$ carriers have an even higher odds ratio than Caucasian Americans. The data roughly showed that, with respect to ancestry difference, APOE $\varepsilon 4$ frequency is inversely associated with the $\varepsilon 4$-related $\mathrm{AD}$ risk, implying that the APOE gene polymorphism partially contributes to the vulnerability to diseases like AD. In two cohort studies by Tang et al. and Evans et al., APOE $\varepsilon 4$ was found to cause a lower increase in $\mathrm{AD}$ incidence in Africans than in Caucasians, despite African Americans bearing higher basal $\mathrm{AD}$ incidence $[32,35]$.

The mechanisms underlying the distinct ancestry-specific $\varepsilon 4$-related AD risk remains unclear, but genetic research has provided insightful explanations regarding this issue. By comparing the association between SNPs and odds ratios in respect of $\mathrm{AD}$, researchers have found that variations in the region surrounding the $A P O E$ gene accounts for most of the ethnicity-specific APOE effect on AD. Blue et al. compared 3,067 Caribbean Hispanics with 3,028 Europeans concerning the APOE genotype, local ancestry, genome-wide ancestry, and AD risk [36]. They discovered that local ancestry shows the strongest association (odds ratio, $\mathrm{OR}=0.61$ ) with $\mathrm{AD}$ risk other than the $\varepsilon 4 \varepsilon 4$ genotype $(\mathrm{OR}=8.59)$, while the impact of genome-wide ancestry is much less $(\mathrm{OR}=1.004)$. Rajabli et al. used 5,496 African American and 389 Puerto Rican individuals to analyze the effect of local ancestry and global ancestry on $A P O E$ \&4-related AD risk. They found that only local ancestry has a significant influence $(P=$ 0.019) [37]. Cornejo-Olivas et al. conducted genome-wide genotyping in the Peruvian population. They reported that 


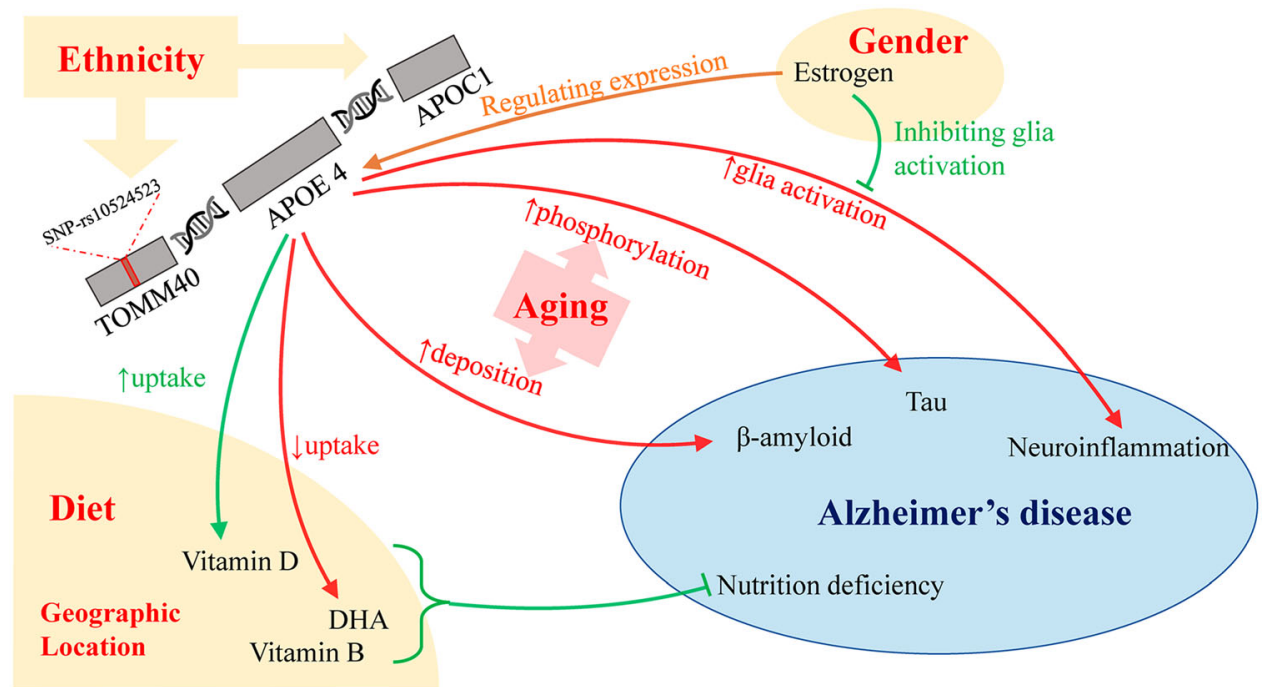

Fig. 1 Interaction of confounding factors with the APOE $\varepsilon 4$ allele and Alzheimer's disease (AD). APOE $\varepsilon 4$ influences AD through regulation of $\beta$-amyloid and tau deposition, neuroinflammation, and neuronal nutrition. Confounding factors may influence the $\varepsilon 4-A D$ association though the following mechanisms: ethnicity impacts the local ancestry of the APOE gene and thus AD risk; gender acts with

the ancestry local to the $A P O E$ gene, rather than the whole genome background, contributes to the $\varepsilon 4$-related $\mathrm{AD}$ risk [38]. Conversely, a few studies have reported that the heterogeneous ancestry-specific APOE $\varepsilon 4$ effect may be derived from different genetic backgrounds or environments. Blue et al. noted that European carriers have a three times higher OR than the Hispanic population even when they share the same origin of $\varepsilon 4$ allele [36]. By genetic screening in specific Arabic populations with high $\mathrm{AD}$ incidence, Farrer and colleagues discovered that the elevated $\mathrm{AD}$ risk has little connection with $\varepsilon 4$ but plausible connections with other genetic or environmental factors [39].

To further understand why genetic polymorphisms local to the $A P O E$ gene cause ethnic differences, we might first turn to genome-wide association sequencing and phylogenetic research regarding the detection of $\mathrm{AD}$ risk factors. To date, the polymorphisms found most relevant to APOE and $\mathrm{AD}$ are in the sequences of Translocase of the Outer Mitochondrial Membrane 40 (TOMM40) and apolipoprotein $\mathrm{C} 1$ (APOC1), two flanking genes on each side of the APOE region. In 1998, Lai and colleagues finished mapping SNPs around $A P O E$ and established a $4-\mathrm{Mb}$ high-density sequence containing 121 SNPs [40]. Later, their team tested these SNPs for their relevance to AD and identified 2 SNPs in the TOMM40 gene showing a strong association with both $\varepsilon 4$ allele and $\mathrm{AD}$ risk [41]. Roses et al. reported one polymorphism, rs10524523, located in intron 6 of TOMM40, defined by the length of its polyT tract, to be closely associated with the age at $\mathrm{AD}$ onset the effects of hormones, mainly estrogen, to change APOE expression and neuroinflammation; aging directly enhances proteinopathy; diet and geographic location alter the nutritional status, jointly with APOE. APOE, apolipoprotein E; TOMM40, Translocase of the Outer Mitochondrial Membrane 40; APOC1, apolipoprotein C1; DHA, docosahexaenoic acid.

[42]. After that, surging amounts of evidence showing the interaction between TOMM 40 and $\mathrm{AD}$ have been published, suggesting that the TOMM40/APOE alleles are better predictors of disease onset than $A P O E$ alone [43]. Interestingly, the rs 10524523 polymorphism is significantly distinct between different ethnicities, which might explain the inconsistent effect of $A P O E$ polymorphism on ethnicity [43]. Specifically, about half of the APOE $\varepsilon 4$ alleles of African Americans are linked with the $\mathrm{S}$ allele of TOMM40, which is associated with a lower risk or reduced onset of $\mathrm{AD}$ than its counterpart, the $\mathrm{L}$ allele. In contrast, only $2 \%$ of the APOE \&4 alleles of Caucasians are linked with the $\mathrm{S}$ allele. However, whether the action of TOMM40 polymorphism depends on APOE remains obscure. Although Caselli et al. reported that TOMM40 influences the decline in cognitive performance in non-AD subjects in an $A P O E$-independent manner [44], more evidence is required to verify the interaction between $A P O E$ and TOMM40. These two genes are in linkage disequilibrium. Zhou et al. reported that variation in $\mathrm{APOC} 1$ confers an $\varepsilon 4$-independent risk of $\mathrm{AD}$, and the distribution of the APOC1 polymorphism, not surprisingly, varies significantly in different ethnicities [45]. To sum up, polymorphisms in TOMM40 and APOC1 may explain ethnicity-related $\mathrm{AD}$ risks, but the underlying mechanisms need further studies. 
Table 1 Frequency of APOE $\varepsilon 4$ allele in different ethnic groups.

\begin{tabular}{|c|c|c|c|c|c|}
\hline Ethnicity & Country & $\begin{array}{l}\text { APOE } \varepsilon 4 \text { frequency in the entire } \\
\text { population }\end{array}$ & $\begin{array}{l}\text { AD risk OR } \\
(\varepsilon 3 \varepsilon 4)\end{array}$ & $\begin{array}{l}\text { AD risk OR } \\
(\varepsilon 4 \varepsilon 4)\end{array}$ & References \\
\hline African & USA & 19.0 & 1.1 & 5.7 & Farrer L.A. et al., 1997 [8] \\
\hline Caucasian & Multinational & 13.7 & 2.7 & 12.5 & Farrer L.A. et al., 1997 \\
\hline Hispanic & Multinational & 11.0 & 2.2 & 2.2 & Farrer L.A. et al., 1997 \\
\hline Japanese & Japan & 8.9 & 5.6 & 33.1 & Farrer L.A. et al., 1997 \\
\hline $\begin{array}{c}\text { Chinese } \\
\text { (Han) }\end{array}$ & China & 13.5 & 2.7 & 8.3 & Tan L. et al., 2013 [28] \\
\hline Indian & India & $7.0-12.7$ & 4.2 & 4.8 & $\begin{array}{l}\text { Agarwal R. et al., } 2014 \\
\text { [29] }\end{array}$ \\
\hline Chilean & Chile & 19 & 2.4 & 12.8 & Quiroga P. et al., 1999 [30] \\
\hline Iranian & Iran & $2.6-6.7$ & 3.7 & 7.5 & $\begin{array}{l}\text { Abyadeh M. et al., } 2019 \\
\text { [31] }\end{array}$ \\
\hline
\end{tabular}

APOE, apolipoprotein E; AD, Alzheimer's disease; OR, odds ratio.

\section{Gender and APOE}

In medical studies, gender represents the identity defined by the biological distinction between male and female, which results from differences in expression of genderrelated genes, gonadal development, and hormone levels [46].

Tremendous efforts have been made to establish the correlation between gender and AD risk. A large population-based study in the USA reported that $2 / 3$ of all AD patients are female, and the longer average life span of women is the most probable cause. In respect of agestratified AD risk, the specific impact of gender remains debatable. In Europe, most researchers have reported that women suffer a higher incidence of $\mathrm{AD}$, and this phenomenon is more evident in the oldest group ( $>75$ years) [47-49]. Research conducted in Asian countries such as Japan [37] and China [38] found consistent result, while in the USA, most studies on this topic, including the MoVIES Project, the Framingham study, and the Baltimore Longitudinal Study, failed to reach the same conclusion [50-52].

Since the connection of the APOE gene and AD was established, researchers have focused on the genderdependent effect on APOE function. Payami and colleagues first reported that the $A P O E \& 4$ allele, especially in heterozygous carriers, confers more $\mathrm{AD}$ risk on female carriers than males [53]. After that, the meta-analysis by Farrer et al., collecting data from $>5,000$ AD patients, concluded that female $\varepsilon 4$ carriers face a larger increase of $\mathrm{AD}$ risk than their male counterparts, as illustrated by the age-stratified OR curve [8]. Subsequent research confirmed this conclusion, and it has become clearer that male carriers with one copy of $\varepsilon 4$ have the same AD risk as non-carriers $[54,55]$. Besides cross-sectional studies, a longitudinal study by Altmann el al., which focused on the speed at which healthy people convert to cognitive impairment during aging, also demonstrated a stronger effect of $A P O E$ $\varepsilon 4$ on women [56]. A recent study analyzing the chromatin accessibility landscape in 19 postmortem late-onset $\mathrm{AD}$ brains in comparison with 21 control brains reported that $A P O E$ loci have more pronounced differences in females than in males [57]. While all the donors in this study were homozygous for $A P O E \varepsilon 3$, it will be interesting to find out whether these gender-dependent differences in the chromatin accessibility landscape have any APOE isoformspecific characteristics.

The gender-dependent effect of $A P O E$ on AD-risk is evident, but the mechanism behind it remains vague. Fortunately, both clinical and animal studies have provided clues for a possible explanation. It has gradually become clear that the variation of cerebrospinal fluid (CSF) tau levels in patients according to $A P O E$ gene diversity also occur in a gender-dependent manner. Damoiseaux and colleagues reported a greater elevation of CSF tau, but not $\beta$-amyloid, in female $\varepsilon 4$ carriers, which coincided with the conclusion of Altmann et al. [56, 58]. Hohman et al. summarized the information from several large $A D$ cohorts. They reported a stronger effect of $A P O E \& 4$ in women to cause increased CSF tau, but they failed to find the same difference compared to pathological findings [59]. Later, the same team examined healthy cohorts a with high $\mathrm{A} \beta$ burden and found much earlier tau deposition in women than men. Still, this gender-related effect was found to be independent of APOE genotype [60]. Besides interaction with CSF tau, gender may influence $\mathrm{AD}$ pathogenesis by an estrogenic effect. Specifically, estrogen replacement treatment has been shown to be beneficial for non- $\varepsilon 4$ female carriers while it is detrimental for carriers in terms of cognitive performance and $\mathrm{AD}$ risk [61, 62]. Estrogen may interact with $A P O E$ and $\mathrm{AD}$ risk by multiple 
mechanisms. First, estrogen might directly regulate the expression of both $A P O E$ and APOE receptors. Stone et al. found that estrogen replacement treatment up-regulates the APOE mRNA level in brain tissue, and Wang et al. suggested that this specific regulation occurring in the brain results from the specific distribution of different estrogen receptors in glia [63, 64]. Second, the neurogenetic effect of estrogen is influenced by APOE polymorphism. Estrogen has been reported to promote neurite expansion, which only happens when $A P O E \varepsilon 2$ or $\varepsilon 3$, but not $\varepsilon 4$, is present [65]. Third, estrogen might alleviate the inflammatory response, as NO and cytokine production by immuneactivated microglia, and the APOE $\varepsilon 4$ genotype is reported to inhibit this anti-inflammatory effect [66]. In addition to the tau- and estrogen-related mechanisms discussed above, $\mathrm{Ca}^{2+}$ hyperactivity and the gut microbiome have also been reported to be affected by gender- $A P O E$ association in animal models $[67,68]$.

\section{Aging and APOE}

Aging is one of the most established and crucial risk factors for $\mathrm{AD}$. Epidemiological studies have found that $\mathrm{AD}$ risk increases with age, even in the oldest group ( $>80$ years). The incidence of AD per year gradually grows from $0.6 \%$ in people aged 65 to 69 years, to $3.3 \%$ in persons aged 80 to 84 years, and even higher in persons aged 85 years and older [69].

$A P O E \& 4$ acts synergistically with the process of aging, resulting in a distinctive pattern of $\mathrm{AD}$. First, $A P O E \varepsilon 4$ leads to a more severe phenotype of cognitive decline. A pattern of more cognitive decline, mimicking the process of $\mathrm{AD}$, has been found in clinically normal APOE $\varepsilon 4$ carriers [70]. This cognitive decline was later reported to be strengthened by aging [71]. Second, APOE $\varepsilon 4$ is associated with accelerated augmentation of $\mathrm{AD}$ incidence with age. Qian et al. integrated four large cohorts, and their model showed the hazard ratio of AD per year is positively related to the $\varepsilon 4$ dose $(1.08-1.16,1.51-2.23$, and 2.63-3.57 for 0,1 , and 2 copies) [72]. Third, APOE 84 may have an altered impact on different age groups. A longitudinal study by Bonham manifested a bell-curve association of $\varepsilon 4$-related $\mathrm{AD}$ risk and age. The strongest effect of $\varepsilon 4$ was found in the 70-80 years group, with a peak hazard ratio of 1.8 [73]. However, the difference of $\varepsilon 4$-related AD risk across groups failed to reach significance.

$A P O E$ \&4-related age-dependent $\mathrm{AD}$ risk may be partially explained by accelerated deposition of $A \beta$. Morris et al. examined CSF biomarkers and cerebral $\mathrm{A} \beta$ imaging in healthy subjects grouped by $A P O E$ genotype and demonstrated that $\varepsilon 4$ carriers show a heavier burden of A $\beta 42$ deposition [11]. Notably, in the 45-49 years age group, the $\mathrm{A} \beta$ imaging showed positive findings only in $\varepsilon 4$ carriers $(10.7 \%$ vs $0 \%)$, indicating that $\varepsilon 4$ enhances preclinical AD pathogenesis in adults. Besides, the cortical binding potential of $\mathrm{A} \beta$ markers rises with aging in association with the $\varepsilon 4$ dose $(0.020,0.013$, and 0.003 per year in $\varepsilon 4$ homozygotes, $\varepsilon 4$ heterozygotes, and noncarriers, respectively), suggesting that $\varepsilon 4$ significantly aggravates the progress of AD pathology. Similar effects on other $\mathrm{AD}$ pathologies have also been reported in $\mathrm{AD}$ patients carrying the $\varepsilon 4$ allele [74]. Several studies have reported that a similar pattern of tau deposition is seen in $\varepsilon 4$ carriers [75, 76], but this has been challenged by other studies. Proteinopathy of tau and $A \beta$ is widely recognized to act in an age-dependent manner [77]; APOE seems to influence aging-related $\mathrm{AD}$ by regulating tau and $\mathrm{A} \beta$ metabolism.

\section{Diet and APOE}

Since no current medication can stop or reverse the progress of $\mathrm{AD}$, an increasing number of studies (mainly cross-sectional) have been carried out to uncover the exact role of diet in modulating the course of the disease. Diverse nutrients such as vitamins, antioxidants, and lipids, generally recognized as necessities in brain development and regeneration, came first when searching for AD modifiers. Researchers found that specific types of nutrient impacted the risk of cognitive decline and $\mathrm{AD}$ risk. Vitamin B, especially folate and niacin, was reported to be protective against cognitive decline in two observational studies on young adults and older people [78, 79]. Randomized clinical trials testing folic acid supplementation in the elderly revealed the positive effect of maintaining cognitive ability [80]. Vitamin D deficiency, defined as serum vitamin $\mathrm{D}<10 \mathrm{ng} / \mathrm{mL}$, was shown to be hazardous for $\mathrm{AD}$ according to several cohort studies [81], and Zhao et al. conducted a prospective cohort study that verified that high vitamin D supplementation is protective against dementia [82]. Omega-3 fatty acids from seafood is another component found to be beneficial by inhibiting cognitive decline. Zhang et al. summarized 21 cohorts to conclude that a diet with a higher intake of fish, omega-3 fatty acids, or docosahexaenoic acid (DHA, the major component of dietary omega-3 fatty acids) leads to a lower risk of $\mathrm{AD}$ [83], and clinical trials supported the mentally protective effect of DHA in DHA-deficient people [84]. Besides single nutrients, dietary patterns have also been frequently tested for their possible effect on cognitive function. The Mediterranean diet, the Dietary Approaches to Stop Hypertension (DASH) diet, and the Mediterranean-DASH Intervention for Neurodegenerative Delay (MIND) diet have been the major focus of research. Besides fruits, 
vegetables, and whole-grains, the Mediterranean diet features the consumption of olive oil, plant protein, and seafood, and the DASH diet emphasizes a reduction of saturated and trans lipids, sodium, and sugar intake; whereas the MIND diet is a combination of the former two diets [85]. Numerous cross-sectional studies and several clinical trials have reported that adopting the Mediterranean diet reduces the risk of both cognitive decline and AD [86-88]. Studies focusing on the DASH diet reported that lower sodium intake is associated with better executive functions. Further studies have reported that MIND has a better protective effect against AD than the Mediterranean or DASH diet [89, 90]. Moreover, the ketogenic diet or supplementation with the ketogenic medium are associated with cognitive improvement and a lower risk of $\mathrm{AD}$, with a deceleration of tau and $\mathrm{A} \beta$ accumulation in the brain [91, 92].

The benefits gained from diets against $\mathrm{AD}$ seem to partially depend on APOE polymorphisms. Deficiency of vitamin B12 and vitamin D are both associated with weaker cognitive function based on observational studies, and this is more evident in $A P O E \& 4$ carriers [93, 94]. Notably, $A P O E \& 4$ is associated with a lower risk of vitamin D deficiency [95]. The majority of studies examining omega-3 fatty acid supplements reported that its benefits are restricted to only $\varepsilon 4$ carriers. In a large longitudinal study of the elderly population conducted by Ondine van de Rest et al. [96], weekly seafood consumption with the optimal amount of omega-3 fatty acid intake from food was found to enhance global and several cognitive domains of cognitive function in $\varepsilon 4$ carriers. Cross-sectional analyses of deceased subjects reported that weekly seafood consumption was associated with fewer pathological AD findings by autopsy only in $\varepsilon 4$ carriers [97]. A randomized clinical trial in younger groups demonstrated that 6 months of DHA supplementation conferred better cognitive performance [98]. Carbohydrate intake could be another dietary factor involved in $A P O E$ dependent $\mathrm{AD}$ risk. Gendreau et al. reported that the glycemic load in the afternoon (mostly representing afternoon snacks) had a synergic effect with $\varepsilon 4$ to elevate $\mathrm{AD}$ risk [99]. In another recent report, both Mediterranean and MIND diet patterns are more beneficial to $\varepsilon 4$ carriers, as was found by Debora et al. when examining the association between MIND diet score and cognitive assessment in the Framingham Heart Study [100].

The interaction of $\mathrm{AD}$ and diet might function in different manners. APOE $\varepsilon 4$ has been reported to elevate the serum level of vitamin D [93], indicating a putative protective effect. We postulate that $A P O E \& 4$ regulates vitamin $\mathrm{D}$ transport, conferring resistance to vitamin $\mathrm{D}$ deficiency. Therefore, low serum vitamin $\mathrm{D}$ in $A P O E \& 4$ carriers might manifest a more severe undernutrition condition. For saturated fatty acids, Hanson et al. reported that the CSF levels of lipids deplete $A \beta$, which is hazardous for $\mathrm{AD}$ pathogenesis, and that this is closely associated with the $A P O E$ genotype and excessive intake of dietary saturated fatty acids [101]. They proposed that collaboration of the $A P O E \varepsilon 4$ allele and dietary saturated fatty acids leads to less lipidation of CSF $A \beta$, which results in less $A \beta$ binding to APOE and more deposition of toxic $A \beta$ [101]. For unsaturated fatty acids, omega- 3 fatty acids, Yassine and colleagues proposed that $\varepsilon 4$ interferes with DHA metabolism, having a neurotoxic effect at an early stage of neurodegeneration [102]. Yassine et al. deduced that: (1) DHA is catabolized faster in $\varepsilon 4$ carriers [103], possibly because very low-density lipoprotein is catabolized faster than high-density lipoprotein in the liver, and preferential binding with the very low-density lipoprotein of $\varepsilon 4$ thus facilitates lipid transport and catabolism, including DHA consumption; (2) $\varepsilon 4$ damages the blood-brain barrier integrity, which inhibits the cerebral uptake of DHA; and (3) $\varepsilon 4$ is associated with less lipidation and decelerates the transfer of lipids in the central nervous system. The above led to the conclusion that $A P O E \varepsilon 4$ lowers CSF DHA, playing a crucial role in $\mathrm{AD}$ pathogenesis. In addition, DHA is widely known for its anti-inflammatory effect [104] and acts by mediating activated microglia [105]. Bos et al. demonstrated that supplementation with DHA through upregulation of peroxisome proliferator-activated receptor-gamma (PPAR- $\gamma$ ), mitigates inflammation in $\varepsilon 4$ carriers [106]. For carbohydrates, Zhao et al. reported that APOE $\varepsilon 4$ in mice impairs the insulin pathway by trapping the insulin receptors in endosomes [107], and hyperglycemia, in turn, facilitates the glycation of APOE and exacerbates AD pathogenesis [108], so that carbohydrate intake elevates $\mathrm{AD}$ risk synergistically with $\mathrm{APOE} \varepsilon 4$.

\section{Geographical Location and APOE}

A limited number of studies indicate that geographical factors modify the pathogenesis or progress of AD. Most studies have reported a positive correlation of residential altitude with the severity of cognitive impairment. In the comparison of a population living at low altitude $(500 \mathrm{~m})$, Bolivians living at high altitude $(3,700 \mathrm{~m})$ have a slower processing speed and reduced attention, independent of age and ancestry [109]. Hota et al. reported that after living at high altitude for one year, acclimatized lowlanders are more susceptible to cognitive decline [110]. Conversely, Thielke et al. reported that, in California counties, the mortality rate attributed to $\mathrm{AD}$ is inversely associated with the altitude of residence, which fits their theory that long terms of hypoxia might slow the progress of AD [111]. Russ and colleagues explored dementia standardized 
mortality ratios in Italy and New Zealand and concluded that living at higher latitudes is associated with higher mortality of dementia [112].

Since few studies have concentrated on the interaction between geographic location, $A P O E$, and $\mathrm{AD}$, the distribution of $A P O E$ polymorphisms might help us to deduce how the $A P O E$ effect is modified by altitude and latitude. Epidemiological data suggest that geographical factors distinctly shape the distribution of APOE polymorphisms. In Europe and Asia, the $A P O E \& 4$ allele frequency is positively correlated with latitude $[113,114]$ : the lowest value is $<10 \%$ in the Mediterranean area and South China, and gradually ascends to $25 \%$ in northern areas. This gradient suggests that a low latitude might enhance the pathogenic effect of $\varepsilon 4$.

It is hard to explicitly determine how altitude or latitude factors affect $A P O E$-related $\mathrm{AD}$ risk due to the many cofounders such as ethnicity, diet, and economy. However, the geographical distribution of $A P O E$ may shed light on the mechanism. Vitamin D production by ultraviolet light and temperature account for the major biological effect of latitude. As noted above, the $\varepsilon 4$ allele is associated with a higher level of serum vitamin D [115], which may explain why northern populations that receive less UV light exhibit a higher frequency of $A P O E \& 4$. Eisenberg proposed that temperature may also contribute to the geographic distribution of $A P O E$ in that people in tropical areas display faster lipid depletion, thus favoring $A P O E$ \&3 [116]. Although little evidence supports the interaction of $A P O E$ and altitude, considering that hypoxia-induced cognitive impairment is regulated by the APOE genotype [117], $A P O E \& 4$ may be less frequent in highland populations.

\section{Conclusions}

In this review, we summarized the major confounding factors that might influence the $A P O E$ genotype-associated $\mathrm{AD}$ risk and discussed plausible mechanisms behind these factor-factor interactions. Ethnicity, gender, and age, as observational factors, clearly alter the $A P O E$-dependent risk, mainly through variation in local ancestry, hormones, and aging-related proteinopathy, respectively. Diet and geographic location, as interventional factors, are complicated due to their interaction with other confounding factors. However, clinical trials provide evidence verifying that certain subfactors, such as vitamin D, DHA, latitude, and altitude, can influence $\varepsilon 4$-related $\mathrm{AD}$ risk to some extent.

Since the last several decades have seen repetitive failures to develop $A \beta$ - or tau-targeted therapies for $A D$, strategies besides decreasing fibril aggregation are gaining popularity, including APOE-targeted therapies. Based on several putative roles that APOE plays in AD pathology, current research mainly focuses on the following strategies: increasing APOE levels and its lipidation [118], blocking APOE and A $\beta$ interaction [119], and using APOE mimetics [120]. We hope the factors discussed in this review may serve to better evaluate APOE-targeted therapies or the grouping of subjects. On the other hand, APOE genotype has been applied in almost all AD risk-prediction models, and researchers are still searching for a better model to elaborate the effect of APOE [121], where stratification by the confounding factors discussed in our review should be the first consideration.

Limitations in this review should be noted. First, considering the wide range of potential factors involved in this topic, certain factors or their corresponding supportive evidence could be missed. Second, studies brought into our review are mostly cross-sectional, with extensively varied study designs and subject conditions, which may compromise our conclusion. Thirdly, as mentioned above, numerous APOE-modifying factors could interact with each other, making the epidemiological evidence less convincing, since the inclusion of all related factors seems impossible in clinical studies. Further clinical trials and meta-analyses are needed for better stratification and regression of numerous factors. Moreover, a surging number of studies concerning APOE and AD is in progress or in the planning stage, and when their results come out, we could have a more comprehensive understanding of this topic.

To sum up, several factors act as a modifier of $\varepsilon 4$-related risk, and they deserve more attention for further studies focusing on APOE, from both the investigative and clinical aspects. Since a growing number of therapies targeting APOE are being developed and tested clinically [122], those APOE-modifying factors should serve as new targets for treatment or reference for population stratification.

Acknowledgements We thank Professor Hongmei Li from Department of Neuroscience, Mayo Clinic and Yingjun Zhao from Fujian Provincial Key Laboratory of Neurodegenerative Disease and Aging Research, Institute of Neuroscience, School of Medicine, Xiamen University for their critical review of this manuscript. This work was supported by the Chengdu Science and Technology Bureau (2019YF05-00655-SN), Key Project of the Medical Science Department, University of Electronic Science and Technology of China (ZYGX2020ZB035) and Guangdong Provincial Key R\&D Program (2018B030337001).

Competing interests The authors declare that they have no conflict of interest.

Open Access This article is licensed under a Creative Commons Attribution 4.0 International License, which permits use, sharing, adaptation, distribution and reproduction in any medium or format, as long as you give appropriate credit to the original author(s) and the source, provide a link to the Creative Commons licence, and indicate 
if changes were made. The images or other third party material in this article are included in the article's Creative Commons licence, unless indicated otherwise in a credit line to the material. If material is not included in the article's Creative Commons licence and your intended use is not permitted by statutory regulation or exceeds the permitted use, you will need to obtain permission directly from the copyright holder. To view a copy of this licence, visit http://creativecommons. org/licenses/by/4.0/.

\section{References}

1. Le WD. Inauguration of a unique journal Ageing and Neurodegenerative Diseases: A new beginning seeking cures for agerelated neurodegenerative diseases. Ageing Neurodegener Dis 2021, https://doi.org/10.20517/and.2021.01.

2. DeTure MA, Dickson DW. The neuropathological diagnosis of Alzheimer's disease. Mol Neurodegener 2019, 14: 32.

3. Hebert LE, Weuve J, Scherr PA, Evans DA. Alzheimer disease in the United States (2010-2050) estimated using the 2010 census. Neurology 2013, 80: 1778-1783.

4. Hauser PS, Narayanaswami V, Ryan RO. Apolipoprotein E: From lipid transport to neurobiology. Prog Lipid Res 2011, 50: 62-74.

5. Li ZH, Shue F, Zhao N, Shinohara M, Bu GJ. APOE2: Protective mechanism and therapeutic implications for Alzheimer's disease. Mol Neurodegener 2020, 15: 63.

6. Najm R, Jones EA, Huang YD. Apolipoprotein E4, inhibitory network dysfunction, and Alzheimer's disease. Mol Neurodegener 2019, 14: 24.

7. Belloy ME, Napolioni V, Greicius MD. A quarter century of APOE and Alzheimer's disease: Progress to date and the path forward. Neuron 2019, 101: 820-838.

8. Farrer LA, Cupples LA, Haines JL, Hyman B, Kukull WA, Mayeux R. Effects of age, sex, and ethnicity on the association between apolipoprotein E genotype and Alzheimer disease. A meta-analysis. APOE and Alzheimer Disease Meta Analysis Consortium. JAMA 1997, 278: 1349-1356.

9. Rahman MM, Lendel C. Extracellular protein components of amyloid plaques and their roles in Alzheimer's disease pathology. Mol Neurodegener 2021, 16: 59.

10. Holtzman DM, Bales KR, Tenkova T, Fagan AM, Parsadanian $\mathrm{M}$, Sartorius LJ, et al. Apolipoprotein E isoform-dependent amyloid deposition and neuritic degeneration in a mouse model of Alzheimer's disease. Proc Natl Acad Sci U S A 2000, 97 : 2892-2897.

11. Morris JC, Roe CM, Xiong C, Fagan AM, Goate AM, Holtzman DM, et al. APOE predicts amyloid-beta but not tau Alzheimer pathology in cognitively normal aging. Ann Neurol 2010, 67: 122-131.

12. Rebeck GW, Reiter JS, Strickland DK, Hyman BT. Apolipoprotein E in sporadic Alzheimer's disease: Allelic variation and receptor interactions. Neuron 1993, 11: 575-580.

13. Cho HS, Hyman BT, Greenberg SM, Rebeck GW. Quantitation of apoE domains in Alzheimer disease brain suggests a role for apoE in Abeta aggregation. J Neuropathol Exp Neurol 2001, 60: 342-349.

14. Garai K, Verghese PB, Baban B, Holtzman DM, Frieden C. The binding of apolipoprotein $\mathrm{E}$ to oligomers and fibrils of amyloid$\beta$ alters the kinetics of amyloid aggregation. Biochemistry 2014, 53: 6323-6331.

15. Castellano JM, Kim J, Stewart FR, Jiang H, DeMattos RB, Patterson BW, et al. Human apoE isoforms differentially regulate brain amyloid- $\beta$ peptide clearance. Sci Transl Med 2011, 3: 89ra57.
16. Hashimoto T, Serrano-Pozo A, Hori Y, Adams KW, Takeda S, Banerji AO, et al. Apolipoprotein E, especially apolipoprotein $\mathrm{E} 4$, increases the oligomerization of amyloid $\beta$ peptide. J Neurosci 2012, 32: 15181-15192.

17. Ma QY, Zhao Z, Sagare AP, Wu YX, Wang M, Owens NC, et al. Blood-brain barrier-associated pericytes internalize and clear aggregated amyloid- $\beta 42$ by LRP1-dependent apolipoprotein E isoform-specific mechanism. Mol Neurodegener 2018, 13: 57.

18. Zhao N, Ren YX, Yamazaki Y, Qiao WH, Li FY, Felton LM, et al. Alzheimer's risk factors age, APOE genotype, and sex drive distinct molecular pathways. Neuron 2020, 106: 727-742.e6.

19. Berger M, Cooter M, Roesler AS, Chung S, Park J, Modliszewski JL, et al. APOE4 copy number-dependent proteomic changes in the cerebrospinal fluid. J Alzheimers Dis 2021, 79: 511-530.

20. Main BS, Villapol S, Sloley SS, Barton DJ, Parsadanian M, Agbaegbu C, et al. Apolipoprotein E4 impairs spontaneous blood brain barrier repair following traumatic brain injury. Mol Neurodegener 2018, 13: 17.

21. Wang SW, Li BY, Solomon V, Fonteh A, Rapoport SI, Bennett $\mathrm{DA}$, et al. Calcium-dependent cytosolic phospholipase $\mathrm{A}_{2}$ activation is implicated in neuroinflammation and oxidative stress associated with ApoE4. Mol Neurodegener 2021, 16: 26.

22. Liu TF, Zhu B, Liu Y, Zhang XM, Yin J, Li XG, et al. Multiomic comparison of Alzheimer's variants in human ESCderived microglia reveals convergence at APOE. J Exp Med 2020, 217: e20200474.

23. Bell RD, Winkler EA, Singh I, Sagare AP, Deane R, Wu ZH, et al. Apolipoprotein E controls cerebrovascular integrity via cyclophilin A. Nature 2012, 485: 512-516.

24. Liu YH, Jiao SS, Wang YR, Bu XL, Yao XQ, Xiang Y, et al. Associations between ApoE\&4 carrier status and serum BDNF levels-new insights into the molecular mechanism of ApoEc4 actions in Alzheimer's disease. Mol Neurobiol 2015, 51: 1271-1277.

25. Theendakara V, Patent A, Peters Libeu CA, Philpot B, Flores S, Descamps $\mathrm{O}$, et al. Neuroprotective Sirtuin ratio reversed by ApoE4. Proc Natl Acad Sci U S A 2013, 110: 18303-18308.

26. Farmer BC, Williams HC, Devanney NA, Piron MA, Nation GK, Carter DJ, et al. APOE4 lowers energy expenditure in females and impairs glucose oxidation by increasing flux through aerobic glycolysis. Mol Neurodegener 2021, 16: 1-18.

27. Corbo RM, Scacchi R. Apolipoprotein E (APOE) allele distribution in the world Is APOE*4 a 'thrifty' allele? Ann Hum Genet 1999, 63: 301-310.

28. Tan L, Yu JT, Zhang W, Wu ZC, Zhang Q, Liu QY, et al. Association of GWAS-linked loci with late-onset Alzheimer's disease in a northern Han Chinese population. Alzheimers Dement 2013, 9: 546-553.

29. Agarwal R, Tripathi CB. Association of apolipoprotein E genetic variation in Alzheimer's disease in Indian population: A meta-analysis. Am J Alzheimers Dis Other Demen 2014, 29 : $575-582$.

30. Quiroga P, Calvo C, Albala C, Urquidi J, Santos JL, Pérez H, et al. Apolipoprotein E polymorphism in elderly Chilean people with Alzheimer's disease. Neuroepidemiology 1999, 18: 48-52.

31. Abyadeh M, Djafarian K, Heydarinejad F, Alizadeh S, ShabBidar S. Association between apolipoprotein E gene polymorphism and Alzheimer's disease in an Iranian population: A meta-analysis. J Mol Neurosci 2019, 69: 557-562.

32. Tang MX, Cross P, Andrews H, Jacobs DM, Small S, Bell K, et al. Incidence of $\mathrm{AD}$ in African-Americans, Caribbean hispanics, and caucasians in northern Manhattan. Neurology 2001, 56: 49-56. 
33. Mayeda ER, Glymour MM, Quesenberry CP, Whitmer RA. Inequalities in dementia incidence between six racial and ethnic groups over 14 years. Alzheimers Dement 2016, 12: 216-224.

34. Matthews KA, Xu W, Gaglioti AH, Holt JB, Croft JB, Mack D, et al. Racial and ethnic estimates of Alzheimer's disease and related dementias in the United States (2015-2060) in adults aged $\geq 65$ years. Alzheimers Dement 2019, 15: 17-24.

35. Evans DA, Bennett DA, Wilson RS, Bienias JL, Morris MC, Scherr PA, et al. Incidence of Alzheimer disease in a biracial urban community: Relation to apolipoprotein E allele status. Arch Neurol 2003, 60: 185-189.

36. Blue EE, Horimoto ARVR, Mukherjee S, Wijsman EM, Thornton TA. Local ancestry at APOE modifies Alzheimer's disease risk in Caribbean Hispanics. Alzheimers Dement 2019, 15: 1524-1532.

37. Rajabli F, Feliciano BE, Celis K, Hamilton-Nelson KL, Whitehead PL, Adams LD, et al. Ancestral origin of ApoE $\varepsilon 4$ Alzheimer disease risk in Puerto Rican and African American populations. PLoS Genet 2018, 14: e1007791. https://doi.org/10. 1371/journal.pgen.1007791.

38. Marca-Ysabel MV, Rajabli F, Cornejo-Olivas M, Whitehead PG, Hofmann NK, Illanes Manrique MZ, et al. Dissecting the role of Amerindian genetic ancestry and the ApoE $\varepsilon 4$ allele on Alzheimer disease in an admixed Peruvian population. Neurobiol Aging 2021, 101: 298-315.

39. Farrer LA, Friedland RP, Bowirrat A, Waraska K, Korczyn A, Baldwin CT. Genetic and environmental epidemiology of Alzheimer's disease in arabs residing in Israel. J Mol Neurosci 2003, 20: 207-212.

40. Lai E, Riley J, Purvis I, Roses A. A 4-Mb high-density single nucleotide polymorphism-based map around human APOE. Genomics 1998, 54: 31-38.

41. Martin ER, Lai EH, Gilbert JR, Rogala AR, Afshari AJ, Riley J, et al. SNPing away at complex diseases: Analysis of singlenucleotide polymorphisms around APOE in Alzheimer disease. Am J Hum Genet 2000, 67: 383-394.

42. Roses AD, Lutz MW, Amrine-Madsen H, Saunders AM, Crenshaw DG, Sundseth SS, et al. A TOMM40 variable-length polymorphism predicts the age of late-onset Alzheimer's disease. Pharmacogenomics J 2010, 10: 375-384.

43. Crenshaw DG, Gottschalk WK, Lutz MW, Grossman I, Saunders AM, Burke JR, et al. Using genetics to enable studies on the prevention of Alzheimer's disease. Clin Pharmacol Ther 2013, 93: 177-185.

44. Caselli RJ, Dueck AC, Huentelman MJ, Lutz MW, Saunders AM, Reiman EM, et al. Longitudinal modeling of cognitive aging and the TOMM40 effect. Alzheimers Dement 2012, 8: 490-495.

45. Zhou XP, Chen Y, Mok KY, Kwok TCY, Mok VCT, Guo QH, et al. Non-coding variability at the APOE locus contributes to the Alzheimer's risk. Nat Commun 2019, 10: 3310.

46. Mielke MM, Vemuri P, Rocca WA. Clinical epidemiology of Alzheimer's disease: Assessing sex and gender differences. Clin Epidemiol 2014, 6: 37-48.

47. Fratiglioni L, Viitanen M, von Strauss E, Tontodonati V, Herlitz A, Winblad B. Very old women at highest risk of dementia and Alzheimer's disease: Incidence data from the Kungsholmen Project, Stockholm. Neurology 1997, 48: 132-138.

48. Ott A, Breteler MM, van Harskamp F, Stijnen T, Hofman A. Incidence and risk of dementia. The Rotterdam Study. Am J Epidemiol 1998, 147: 574-580.

49. Letenneur L, Gilleron V, Commenges D, Helmer C, Orgogozo JM, Dartigues JF. Are sex and educational level independent predictors of dementia and Alzheimer's disease? Incidence data from the PAQUID project. J Neurol Neurosurg Psychiatry 1999, 66: $177-183$.
50. Ganguli M, Dodge HH, Chen P, Belle S, DeKosky ST. Ten-year incidence of dementia in a rural elderly US community population: The MoVIES Project. Neurology 2000, 54: $1109-1116$.

51. Kawas C, Gray S, Brookmeyer R, Fozard J, Zonderman A. Agespecific incidence rates of Alzheimer's disease: The Baltimore Longitudinal Study of Aging. Neurology 2000, 54: 2072-2077.

52. Bachman DL, Wolf PA, Linn RT, Knoefel JE, Cobb JL, Belanger AJ, et al. Incidence of dementia and probable Alzheimer's disease in a general population: The Framingham Study. Neurology 1993, 43: 515-519.

53. Payami H, Montee KR, Kaye JA, Bird TD, Yu CE, Wijsman $\mathrm{EM}$, et al. Alzheimer's disease, apolipoprotein $\mathrm{E} 4$, and gender. JAMA 1994, 271: 1316-1317.

54. Bretsky PM, Buckwalter JG, Seeman TE, Miller CA, Poirier J, Schellenberg GD, et al. Evidence for an interaction between apolipoprotein E genotype, gender, and Alzheimer disease. Alzheimer Dis Assoc Disord 1999, 13: 216-221.

55. Breitner JC, Wyse BW, Anthony JC, Welsh-Bohmer KA, Steffens DC, Norton MC, et al. APOE-epsilon4 count predicts age when prevalence of $\mathrm{AD}$ increases, then declines: The Cache County Study. Neurology 1999, 53: 321-331.

56. Altmann A, Tian L, Henderson VW, Greicius MD. Alzheimer's Disease Neuroimaging Initiative Investigators. Sex modifies the APOE-related risk of developing Alzheimer disease. Ann Neurol 2014, 75: 563-573.

57. Barrera J, Song LY, Gamache JE, Garrett ME, Safi A, Yun Y, et al. Sex dependent glial-specific changes in the chromatin accessibility landscape in late-onset Alzheimer's disease brains. Mol Neurodegener 2021, 16: 58.

58. Damoiseaux JS, Seeley WW, Zhou J, Shirer WR, Coppola G, Karydas A, et al. Gender modulates the APOE $\varepsilon 4$ effect in healthy older adults: Convergent evidence from functional brain connectivity and spinal fluid tau levels. J Neurosci 2012, 32: 8254-8262.

59. Hohman TJ, Dumitrescu L, Barnes LL, Thambisetty M, Beecham G, Kunkle B, et al. Sex-specific association of apolipoprotein $\mathrm{E}$ with cerebrospinal fluid levels of tau. JAMA Neurol 2018, 75: 989-998.

60. Buckley RF, Mormino EC, Rabin JS, Hohman TJ, Landau S, Hanseeuw BJ, et al. Sex differences in the association of global amyloid and regional tau deposition measured by positron emission tomography in clinically normal older adults. JAMA Neurol 2019, 76: 542-551.

61. Rippon GA, Tang MX, Lee JH, Lantigua R, Medrano M, Mayeux R. Familial Alzheimer disease in Latinos: Interaction between APOE, stroke, and estrogen replacement. Neurology 2006, 66: 35-40.

62. Kang JH, Grodstein F. Postmenopausal hormone therapy, timing of initiation, APOE and cognitive decline. Neurobiol Aging 2012, 33: 1129-1137.

63. Stone DJ, Rozovsky I, Morgan TE, Anderson CP, Hajian H, Finch CE. Astrocytes and microglia respond to estrogen with increased apoE mRNA in vivo and in vitro. Exp Neurol 1997, 143: 313-318.

64. Wang JM, Irwin RW, Brinton RD. Activation of estrogen receptor alpha increases and estrogen receptor beta decreases apolipoprotein E expression in Hippocampus in vitro and in vivo. Proc Natl Acad Sci USA 2006, 103: 16983-16988.

65. Nathan BP, Barsukova AG, Shen F, McAsey M, Struble RG. Estrogen facilitates neurite extension via apolipoprotein $\mathrm{E}$ in cultured adult mouse cortical neurons. Endocrinology 2004 , 145: 3065-3073.

66. Brown CM, Choi E, Xu Q, Vitek MP, Colton CA. The APOE4 genotype alters the response of microglia and macrophages to 17beta-estradiol. Neurobiol Aging 2008, 29: 1783-1794. 
67. Larramona-Arcas R, González-Arias C, Perea G, Gutiérrez A, Vitorica J, García-Barrera T, et al. Sex-dependent calcium hyperactivity due to lysosomal-related dysfunction in astrocytes from APOE4 versus APOE3 gene targeted replacement mice. Mol Neurodegener 2020, 15: 35.

68. Maldonado Weng J, Parikh I, Naqib A, York J, Green SJ, Estus $\mathrm{S}$, et al. Synergistic effects of APOE and sex on the gut microbiome of young EFAD transgenic mice. Mol Neurodegener 2019, 14: 47.

69. Hebert LE, Scherr PA, Beckett LA, Albert MS, Pilgrim DM, Chown MJ, et al. Age-specific incidence of Alzheimer's disease in a community population. JAMA 1995, 273: 1354-1359.

70. Caselli RJ, Dueck AC, Osborne D, Sabbagh MN, Connor DJ, Ahern GL, et al. Longitudinal modeling of age-related memory decline and the APOE epsilon4 effect. N Engl J Med 2009, 361: 255-263.

71. Williams OA, An Y, Armstrong N, Shafer AT, Helphrey J, Kitner-Triolo M, et al. O4-05-01: Apolipoprotein 84 allele effects on longitudinal cognitive trajectories are sex- and agedependent. Alzheimer's Dement 2019, 15: P1241-P1242.

72. Qian J, Wolters FJ, Beiser A, Haan M, Ikram MA, Karlawish J, et al. APOE-related risk of mild cognitive impairment and dementia for prevention trials: An analysis of four cohorts. PLoS Med 2017, 14: e1002254. https://doi.org/10.1371/journal.pmed. 1002254

73. Bonham LW, Geier EG, Fan CC, Leong JK, Besser L, Kukull WA, et al. Age-dependent effects of APOE $\varepsilon 4$ in preclinical Alzheimer's disease. Ann Clin Transl Neurol 2016, 3: 668-677.

74. Drzezga A, Grimmer T, Henriksen G, Mühlau M, Perneczky R, Miederer I, et al. Effect of APOE genotype on amyloid plaque load and gray matter volume in Alzheimer disease. Neurology 2009, 72: 1487-1494.

75. Quevenco FC, van Bergen JM, Treyer V, Studer ST, Kagerer $\mathrm{SM}$, Meyer R, et al. Functional brain network connectivity patterns associated with normal cognition at old-age, local $\beta$ amyloid, tau, and APOE4. Front Aging Neurosci 2020, 12: 46.

76. Wennberg AM, Tosakulwong N, Lesnick TG, Murray ME, Whitwell JL, Liesinger AM, et al. Association of apolipoprotein E $\varepsilon 4$ with transactive response DNA-binding protein 43. JAMA Neurol 2018, 75: 1347-1354.

77. Lim YY, Ellis KA, Pietrzak RH, Ames D, Darby D, Harrington $\mathrm{K}$, et al. Stronger effect of amyloid load than APOE genotype on cognitive decline in healthy older adults. Neurology 2012, 79: $1645-1652$.

78. Qin B, Xun P, Jacobs DR, Zhu N, Daviglus ML, Reis JP, et al. Intake of niacin, folate, vitamin B-6, and vitamin B-12 through young adulthood and cognitive function in midlife: The Coronary Artery Risk Development in Young Adults (CARDIA) study. Am J Clin Nutr 2017, 106: 1032-1040.

79. Lefèvre-Arbogast S, Féart C, Dartigues JF, Helmer C, Letenneur L, Samieri C. Dietary B vitamins and a 10-year risk of dementia in older persons. Nutrients 2016, 8: E761.

80. Durga J, van Boxtel MP, Schouten EG, Kok FJ, Jolles J, Katan $\mathrm{MB}$, et al. Effect of 3-year folic acid supplementation on cognitive function in older adults in the FACIT trial: A randomised, double blind, controlled trial. Lancet 2007, 369: 208-216.

81. Jayedi A, Rashidy-Pour A, Shab-Bidar S. Vitamin D status and risk of dementia and Alzheimer's disease: A meta-analysis of dose-response. Nutr Neurosci 2019, 22: 750-759.

82. Zhao C, Tsapanou A, Manly J, Schupf N, Brickman AM, Gu Y. Vitamin D intake is associated with dementia risk in the Washington Heights-Inwood Columbia Aging Project (WHICAP). Alzheimers Dement 2020, 16: 1393-1401.

83. Zhang Y, Chen JN, Qiu JN, Li YJ, Wang JB, Jiao JJ. Intakes of fish and polyunsaturated fatty acids and mild-to-severe cognitive impairment risks: A dose-response meta-analysis of 21 cohort studies. Am J Clin Nutr 2016, 103: 330-340.

84. Yurko-Mauro K, McCarthy D, Rom D, Nelson EB, Ryan AS, Blackwell A, et al. Beneficial effects of docosahexaenoic acid on cognition in age-related cognitive decline. Alzheimers Dement 2010, 6: 456-464.

85. Scarmeas N, Anastasiou CA, Yannakoulia M. Nutrition and prevention of cognitive impairment. Lancet Neurol 2018, 17: 1006-1015.

86. $\mathrm{Wu} \mathrm{L}$, Sun D. Adherence to Mediterranean diet and risk of developing cognitive disorders: An updated systematic review and meta-analysis of prospective cohort studies. Sci Rep 2017, 7: 41317.

87. Valls-Pedret C, Sala-Vila A, Serra-Mir M, Corella D, de la Torre R, Martínez-González MÁ, et al. Mediterranean diet and agerelated cognitive decline: A randomized clinical trial. JAMA Intern Med 2015, 175: 1094-1103.

88. Martínez-Lapiscina EH, Clavero P, Toledo E, Estruch R, SalasSalvadó J, San Julián B, et al. Mediterranean diet improves cognition: The PREDIMED-NAVARRA randomised trial. J Neurol Neurosurg Psychiatry 2013, 84: 1318-1325.

89. Morris MC, Tangney CC, Wang YM, Sacks FM, Bennett DA, Aggarwal NT. MIND diet associated with reduced incidence of Alzheimer's disease. Alzheimers Dement 2015, 11: 1007-1014.

90. Hosking DE, Eramudugolla R, Cherbuin N, Anstey KJ. MIND not Mediterranean diet related to 12-year incidence of cognitive impairment in an Australian longitudinal cohort study. Alzheimers Dement 2019, 15: 581-589.

91. Fortier M, Castellano CA, Croteau E, Langlois F, Bocti C, StPierre $\mathrm{V}$, et al. A ketogenic drink improves brain energy and some measures of cognition in mild cognitive impairment. Alzheimers Dement 2019, 15: 625-634.

92. Neth BJ, Mintz A, Whitlow C, Jung Y, Solingapuram Sai K, Register TC, et al. Modified ketogenic diet is associated with improved cerebrospinal fluid biomarker profile, cerebral perfusion, and cerebral ketone body uptake in older adults at risk for Alzheimer's disease: A pilot study. Neurobiol Aging 2020, 86: 54-63.

93. Maddock J, Cavadino A, Power C, Hyppönen E. 25-hydroxyvitamin D, APOE $\varepsilon 4$ genotype and cognitive function: findings from the 1958 British birth cohort. Eur J Clin Nutr 2015, 69: $505-508$.

94. Feng L, Li JL, Yap KB, Kua EH, Ng TP. Vitamin B-12, apolipoprotein $\mathrm{E}$ genotype, and cognitive performance in community-living older adults: Evidence of a gene-micronutrient interaction. Am J Clin Nutr 2009, 89: 1263-1268.

95. Dursun E, Alaylıŏglu M, Bilgiç B, Hanağası H, Lohmann E, Atasoy IL, et al. Vitamin D deficiency might pose a greater risk for ApoE $\varepsilon 4$ non-carrier Alzheimer's disease patients. Neurol Sci 2016, 37: 1633-1643.

96. van de Rest O, Wang YM, Barnes LL, Tangney C, Bennett DA, Morris MC. APOE $\varepsilon 4$ and the associations of seafood and longchain Omega-3 fatty acids with cognitive decline. Neurology 2016, 86: 2063-2070.

97. Morris MC, Brockman J, Schneider JA, Wang Y, Bennett DA, Tangney CC, et al. Association of seafood consumption, brain mercury level, and APOE $\varepsilon 4$ status with brain neuropathology in older adults. JAMA 2016, 315: 489-497.

98. Stonehouse W, Conlon CA, Podd J, Hill SR, Minihane AM, Haskell C, et al. DHA supplementation improved both memory and reaction time in healthy young adults: A randomized controlled trial. Am J Clin Nutr 2013, 97: 1134-1143.

99. Gentreau M, Chuy V, Féart C, Samieri C, Ritchie K, Raymond $\mathrm{M}$, et al. Refined carbohydrate-rich diet is associated with longterm risk of dementia and Alzheimer's disease in apolipoprotein E \&4 allele carriers. Alzheimers Dement 2020, 16: 1043-1053. 
100. van Lent DM, O’Donnell A, Beiser AS, Vasan RS, DeCarli CS, Scarmeas $\mathrm{N}$, et al. Mind diet adherence and cognitive performance in the Framingham heart study. J Alzheimer's Dis 2021, 82: 827-839.

101. Hanson AJ, Bayer-Carter JL, Green PS, Montine TJ, Wilkinson $\mathrm{CW}$, Baker LD, et al. Effect of apolipoprotein E genotype and diet on apolipoprotein E lipidation and amyloid peptides: Randomized clinical trial. JAMA Neurol 2013, 70: 972-980.

102. Yassine HN, Braskie MN, Mack WJ, Castor KJ, Fonteh AN, Schneider LS, et al. Association of docosahexaenoic acid supplementation with alzheimer disease stage in apolipoprotein E $\varepsilon 4$ carriers: A review. JAMA Neurol 2017, 74: 339-347.

103. Chouinard-Watkins R, Rioux-Perreault C, Fortier M, TremblayMercier J, Zhang Y, Lawrence P, et al. Disturbance in uniformly ${ }^{13} \mathrm{C}$-labelled DHA metabolism in elderly human subjects carrying the apoE $\varepsilon 4$ allele. Br J Nutr 2013, 110: 1751-1759.

104. Calder PC. Omega-3 fatty acids and inflammatory processes: From molecules to man. Biochem Soc Trans 2017, 45: $1105-1115$.

105. Fourrier C, Remus-Borel J, Greenhalgh AD, Guichardant M, Bernoud-Hubac N, Lagarde M, et al. Docosahexaenoic acidcontaining choline phospholipid modulates LPS-induced neuroinflammation in vivo and in microglia in vitro. J Neuroinflammation 2017, 14: 170.

106. Bos MM, Noordam R, Blauw GJ, Slagboom PE, Rensen PCN, van Heemst D. The ApoE $\varepsilon 4$ isoform: Can the risk of diseases be reduced by environmental factors? J Gerontol: Ser A 2019, 74: 99-107.

107. Zhao N, Liu CC, van Ingelgom AJ, Martens YA, Linares C, Knight JA, et al. Apolipoprotein E4 impairs neuronal insulin signaling by trapping insulin receptor in the endosomes. Neuron 2017, 96: 115-129.e5.

108. Li YM, Dickson DW. Enhanced binding of advanced glycation endproducts (AGE) by the ApoE4 isoform links the mechanism of plaque deposition in Alzheimer's disease. Neurosci Lett 1997, 226: $155-158$

109. Hill CM, Dimitriou D, Baya WR, Gavlak-Dingle J, Lesperance $\mathrm{V}$, et al. Cognitive performance in high-altitude Andean residents compared with low-altitude populations: From childhood to older age. Neuropsychology 2014, 28: 752-760.

110. Hota SK, Sharma VK, Hota K, Das S, Dhar P, Mahapatra BB, et al. Multi-domain cognitive screening test for neuropsychological assessment for cognitive decline in acclimatized lowlanders staying at high altitude. Indian J Med Res 2012, 136: $411-420$.
111. Thielke S, Slatore CG, Banks WA. Association between alzheimer dementia mortality rate and altitude in California counties. JAMA Psychiatry 2015, 72: 1253-1254.

112. Russ TC, Murianni L, Icaza G, Slachevsky A, Starr JM. Geographical variation in dementia mortality in Italy, new Zealand, and Chile: The impact of latitude, vitamin D, and air pollution. Dement Geriatr Cogn Disord 2016, 42: 31-41.

113. Egert S, Rimbach G, Huebbe P. ApoE genotype: From geographic distribution to function and responsiveness to dietary factors. Proc Nutr Soc 2012, 71: 410-424.

114. Hu P, Qin YH, Jing CX, Lu L, Hu B, Du PF. Does the geographical gradient of ApoE4 allele exist in China? A systemic comparison among multiple Chinese populations. Mol Biol Rep 2011, 38: 489-494.

115. Huebbe P, Nebel A, Siegert S, Moehring J, Boesch-Saadatmandi $\mathrm{C}$, Most E, et al. APOE $\varepsilon 4$ is associated with higher vitamin D levels in targeted replacement mice and humans. FASEB J 2011, 25: 3262-3270.

116. Eisenberg DT, Kuzawa CW, Hayes MG. Worldwide allele frequencies of the human apolipoprotein E gene: Climate, local adaptations, and evolutionary history. Am J Phys Anthropol 2010, 143: 100-111.

117. Kaushal N, Ramesh V, Gozal D. Human apolipoprotein E4 targeted replacement in mice reveals increased susceptibility to sleep disruption and intermittent hypoxia. Am J Physiol Regul Integr Comp Physiol 2012, 303: R19-R29.

118. Cramer PE, Cirrito JR, Wesson DW, Lee CY, Karlo JC, Zinn $\mathrm{AE}$, et al. ApoE-directed therapeutics rapidly clear $\beta$-amyloid and reverse deficits in AD mouse models. Science 2012, 335: 1503-1506.

119. Sawmiller D, Habib A, Hou HY, Mori T, Fan AR, Tian J, et al. A novel apolipoprotein E antagonist functionally blocks apolipoprotein $\mathrm{E}$ interaction with $\mathrm{N}$-terminal amyloid precursor protein, reduces $\beta$-amyloid-associated pathology, and improves cognition. Biol Psychiatry 2019, 86: 208-220.

120. Wang LK, Hou HY, Zi D, Habib A, Tan J, Sawmiller D. Novel apoE receptor mimetics reduce LPS-induced microglial inflammation. Am J Transl Res 2019, 11: 5076-5085.

121. Ebenau JL, van der Lee SJ, Hulsman M, Tesi N, Jansen IE, Verberk IMW, et al. Risk of dementia in APOE $\varepsilon 4$ carriers is mitigated by a polygenic risk score. Alzheimers Dement (Amst) 2021, 13: e12229. https://doi.org/10.1002/dad2.12229.

122. Yamazaki Y, Zhao N, Caulfield TR, Liu CC, Bu GJ. Apolipoprotein E and Alzheimer disease: Pathobiology and targeting strategies. Nat Rev Neurol 2019, 15: 501-518. 